\title{
Echinchrome Pigment Isolated from Sea Urchin Improves Female Rat's Fertility
}

\author{
Eman Y Salah EL-Din, Ayman S Mohamed*, Neveen Asmet Farag and Abdel Rahman A Tawfik \\ Zoology Department, Cairo University, Egypt
}

*Corresponding author: Ayman S Mohamed, Zoology Department, Faculty of Science, Cairo University, Egypt.

To Cite This Article: Ayman S Mohamed. Echinchrome Pigment Isolated from Sea Urchin Improves Female Rat's Fertility. Am J Biomed Sci \& Res. 2019 - 3(2). AJBSR.MS.ID.000651. DOI: 10.34297/AJBSR.2019.03.000651

Received: May 20, 2019 | Published: May 28, 2019

\begin{abstract}
Background: Echinochrome (Ech) is natural product pigment found in sea urchin. The present study aimed to evaluate effect of Ech on fertility of female rats.

Methods: 18 virgin females will assign into 3 groups: Control; received $1 \mathrm{ml}$ 2\% DMSO (orally) daily for 30 days, Low dose Ech; received $1 \mathrm{ml}$ of $0.1 \mathrm{mg} / \mathrm{kg}$ and high dose Ech; received $1 \mathrm{ml}$ of $1 \mathrm{mg} / \mathrm{kg}$ Ech.

Results: High dose of Ech caused significant decrease in levels of glucose, AST, ALT, ALP, Creatinine, Urea, Uric acid, TC, LDL-C, Tg, while TP and albumin and HDL-C increase. Significant increase in FSH, LH, Uterus weight, Body weight gain, Placenta weight, Embryos number, Embryos weight, Embryo length was noticed after treatment with high dose of Ech.
\end{abstract}

Conclusion: Echinchrome ameliorate female rats' fertility through an improvement in sex hormones, lipid profile, glucose level, liver function and kidney functions.

Keywords: Echinochrome; Sea urchin; Infertility; Antioxidant; Rats

\section{Introduction}

Infertility is considering disease which characterized by the failure to establish a clinical pregnancy after one year of regular and unprotected sexual intercourse during the fertile phase of the menstrual cycles [1]. Infertility is a stressful and unexpected experience by a couple and is estimated to affect $8 \%-12 \%$ of couples worldwide [2]. About $15-30 \%$ of the infertile couples are diagnosed with unexplained infertility after basic fertility tests after they cannot achieve a pregnancy due to accident or to undetected causes, including oviduct dysfunction with tubal patency, fertilization failure and implantation failure without an organic lesion [3]. Oxidative stress may contribute to aging and several diseased states affecting female reproduction [4]. Recent reports identified an excessive amount of reactive oxygen species (ROS) caused by alcohol consumption, cigarette smoking, varicocele, and obesity, among other factors, results in infertility [5]. Approximately 190 million patients are infertile worldwide including recurrent implantation failure and recurrent pregnancy loss [6]. Treatment of infertility may use drugs or surgical procedures.

Unfortunately, these treatments are expensive and associated with side effects [7]. Therefore; alternative medicines have proven efficacious in the treatment of infertility. Marine organisms are a wonderful source of biologically active natural products [8]. There is much valuable information for new antibiotic discoveries from sea urchin (Phylum Echinodermata, class Echinoidea), which give new insights into bioactive compounds within it [9]. Sea urchin has a number of unique substances, such as quinonoid pigments named spinochromes [10]. From these compounds, Echinochrome (Ech) which is the most common dark red pigment of sea urchin shells, spines, and eggs [11]. It has ability to improve mitochondrial function in the heart and therapeutic potential against cardio-toxic agent $[12,13]$. In addition, Ech consider strong hypolipidemic agent which also possess ability to improve renal function $[14,15]$. Thus, the present study aimed to evaluate effect of Ech on fertility of female rats.

\section{Methods}

\section{Sea urchin collection}

Sea urchins (Paracentrotus lividu) were collected from the Mediterranean coast of Alexandria (Egypt). They washed with sea water at the collection site to remove sand and overgrowing organisms and transport to the laboratory packed in ice. 


\section{Echinochrome (Ech) extraction}

The internal organs of sea urchins were removed, and then the shells and spines washed with a stream of cold water, air-dried at $4{ }^{\circ} \mathrm{C}$ for 2 days in the dark and then grounded. The powders (50 g) were dissolving by gradually adding $100 \mathrm{ml}$ of $6 \mathrm{M} \mathrm{HCl}$. Three times extraction of the pigments with the same volume of diethyl ether. The ether layer collected washed with $5 \% \mathrm{NaCl}$ until the acid almost removed. The ether solution including the pigments dryad over anhydrous sodium sulfate and the solvent evaporated under reduced pressure. The pigment stored at $-30{ }^{\circ} \mathrm{C}$ in the dark $[16,17]$

\section{Experimental animals}

From the National Research Center (NRC, Dokki, Giza) twenty seven Wistar rats (18 virgin female rats, 7-8 weeks old, 200-220 g; and 9 mature male rats, 14-15 weeks old, 240-260 g) were obtained, transferred to our breeding colony and maintained on a $12 \mathrm{hr}$ light/dark cycle and controlled temperature $\left(23 \pm 2{ }^{\circ} \mathrm{C}\right)$. The animals had given food and water ad libitum.

\section{Reproductive management}

After one week of acclimatization the females were started the oral administration of DMSO, low and high dose of Ech for 30 days. At the end of the month the female's mate with males (2: 1). The presence of sperm in the vaginal lavage will consider day 0 of gestation. If no sperm were observed in the vaginal smears in any of the females within 7 days of mating, the male was replaced by another male.

\section{Ethical consideration and Field study}

Experimental protocols and procedures used in this study were approved by the Cairo University, Faculty of Science, Institutional Animal Care and Use Committee (IACUC) (Egypt) (CUIF718). All the experimental procedures were carried out in accordance with international guidelines for the care and use of laboratory animals.

\section{Experimental design}

a) 18 virgin females will assign into 3 groups (6 rats/ group):

b) Control: Rats received $1 \mathrm{ml} \mathrm{2 \%} \mathrm{DMSO} \mathrm{(orally)} \mathrm{daily} \mathrm{for} 30$ days

c) Low dose Ech: Rats received $1 \mathrm{ml}$ of $0.1 \mathrm{mg} / \mathrm{kg}$ Ech (in $2 \%$ DMSO, orally) daily for 30 days

d) High dose Ech: Rats received $1 \mathrm{ml}$ of $1 \mathrm{mg} / \mathrm{kg}$ Ech (in $2 \%$ DMSO, orally) [14] daily for 30 days.

After thirty days the treated females' rats cohabited with normal males, then the females allowed to complete the pregnant period. At day 20, the animals had euthanatized, and blood sample were collected for biochemical analysis. The fetuses were removed from uterus and were blotted on blotting paper. Embryo number, length and weight were recorded.

\section{Biochemical analyses}

The serum glucose, aspartate aminotransferase (AST), alanine aminotransferase (ALT), alkaline phosphatase (ALP), total bilirubin, total protein, albumin, creatinine, urea, uric acid, total cholesterol (TC), low density lipoprotein (LDL-C), high density lipoprotein (HDL-C), triglycerides (TG), follicular stimulated hormone (FSH), luteinizing hormone ( $\mathrm{LH})$, testosterone were determined according to the manufacturer's instructions using Spectrum Diagnostics and Bio-diagnostic kits (Giza, Egypt).

\section{Statistical analysis}

Values were expressed as means \pm SE. The comparisons within groups were evaluated utilizing one way analysis of variance (ANOVA) with Duncan post hoc test was used to compare the group means and $\mathrm{p}<0.05$ was considered statistically significant. SPSS, for Windows (version 15.0) was used for the statistical analysis.

\section{Results}

\begin{tabular}{|c|c|c|c|}
\hline Table 1: Effect of different doses of Echinochrome $(0.1$ and $1 \mathrm{mg} / \mathrm{kg})$ on biomarkers of female rats. & High dose \\
\hline Parameters & Control & Low dose & $85.00 \pm 1.88^{{ }^{\mathrm{a}}}$ \\
\hline Glucose $(\mathrm{mg} / \mathrm{dl})$ & $94.50 \pm 1.63^{\mathrm{b}}$ & $196.60 \pm 6.09^{\mathrm{b}}$ & $155.75 \pm 2.06^{\mathrm{a}}$ \\
\hline AST (U/ml) & $201.00 \pm 2.70^{\mathrm{b}}$ & $50.20 \pm 1.24^{\mathrm{b}}$ & $40.00 \pm 0.45^{\mathrm{a}}$ \\
\hline ALT (U/ml) & $49.00 \pm 2.66^{\mathrm{b}}$ & $158.00 \pm 2.10^{\mathrm{b}}$ & $132.40 \pm 1.25^{\mathrm{a}}$ \\
\hline ALP (U/L) & $164.75 \pm 4.42^{\mathrm{b}}$ & $0.62 \pm 0.01^{\mathrm{a}}$ & $7.33 \pm 0.09^{\mathrm{b}}$ \\
\hline Bilirubin (mg/dl) & $0.65 \pm 0.01^{\mathrm{a}}$ & $7.04 \pm 0.09^{\mathrm{a}}$ & $3.94 \pm 0.12^{\mathrm{b}}$ \\
\hline TP (g/dl) & $6.88 \pm 0.19^{\mathrm{a}}$ & $3.64 \pm 0.19^{\mathrm{a}}$ & $66.20 \pm 1.36^{\mathrm{a}}$ \\
\hline Albumin (g/dl) & $3.58 \pm 0.07^{\mathrm{a}}$ & $78.60 \pm 1.54^{\mathrm{b}}$ & $35.50 \pm 0.91^{\mathrm{a}}$ \\
\hline TC (mg/dl) & $79.92 \pm 1.69^{\mathrm{b}}$ & $46.34 \pm 2.47^{\mathrm{b}}$ & $49.60 \pm 1.44^{\mathrm{b}}$ \\
\hline LDL-C (mg/dl) & $47.83 \pm 1.87^{\mathrm{b}}$ & $40.20 \pm 1.50^{\mathrm{a}}$ & $158.80 \pm 1.24^{\mathrm{a}}$ \\
\hline HDL-C (mg/dl) & $37.60 \pm 1.66^{\mathrm{a}}$ & $179.40 \pm 2.06^{\mathrm{b}}$ & $40.60 \pm 0.40^{\mathrm{a}}$ \\
\hline TG (mg/dl) & $188.50 \pm 2.25^{\mathrm{b}}$ & $48.40 \pm 1.44^{\mathrm{b}}$ & $0.62 \pm 0.02^{\mathrm{a}}$ \\
\hline Urea(g/dl) & $50.00 \pm 1.10^{\mathrm{b}}$ & $0.77 \pm 0.03^{\mathrm{b}}$ & $4.08 \pm 0.16^{\mathrm{a}}$ \\
\hline Creatinine(mg/dl) & $0.80 \pm 0.03^{\mathrm{b}}$ & $4.84 \pm 0.18^{\mathrm{b}}$ & \\
\hline Uric acid(mg/dl) & $5.10 \pm 0.06^{\mathrm{b}}$ & & \\
\hline
\end{tabular}

Note: Values are means \pm se $(n=6$ per group). Each value not sharing a common letter superscript is significantly different $(P<0.05)$. 
High dose of Ech caused significant $(\mathrm{p}<0.05)$ decrease in levels of glucose, AST, ALT, ALP, Creatinine, Urea, Uric acid, TC, LDL-C, Tg, while TP, Albumin and HDL-C increase (Table 1). Table 2 showed significant increase in FSH, LH, Uterus weight, Body weight gain,
Placenta weight, Embryos number, Embryos weight, Embryo length, while Testosterone decreased after the treatment with high dose Ech.

\begin{tabular}{|c|c|c|c|}
\hline \multicolumn{2}{|c|}{ Table 2: Effect of different doses of Echinochrome $(0.1$ and $1 \mathrm{mg} / \mathrm{kg})$ on Maternal and Fetal outcome of female rats. } \\
\hline Parameters & Control & Low dose & High dose \\
\hline FSH (mIU/ml) & $0.09 \pm 0.01^{\mathrm{a}}$ & $0.08 \pm 0.02^{\mathrm{a}}$ & $0.14 \pm 0.00^{\mathrm{b}}$ \\
\hline LH (mIU/ml) & $0.08 \pm 0.00^{\mathrm{a}}$ & $0.09 \pm 0.01^{\mathrm{a}}$ & $0.83 \pm 0.00^{\mathrm{b}}$ \\
\hline Testosterone (ng/ml) & $1.16 \pm 0.04^{\mathrm{b}}$ & $1.14 \pm 0.07^{\mathrm{b}}$ & $32.22 \pm 0.73^{\mathrm{b}}$ \\
\hline Uterus weight (gm) & $26.14 \pm 0.77^{\mathrm{a}}$ & $28.30 \pm 0.83^{\mathrm{a}}$ & $50.40 \pm 0.68^{\mathrm{b}}$ \\
\hline Body weight gain (gm) & $42.00 \pm 1.67^{\mathrm{a}}$ & $44.60 \pm 0.68^{\mathrm{a}}$ & $0.60 \pm .01^{\mathrm{b}}$ \\
\hline Placenta weight (gm) & $0.489 \pm .02^{\mathrm{a}}$ & $0.52 \pm .03^{\mathrm{a}}$ & $8.40 \pm 0.51^{\mathrm{b}}$ \\
\hline Embryos number & $6.80 \pm 0.51^{\mathrm{a}}$ & $7.10 \pm 0.37^{\mathrm{a}}$ & $2.02 \pm 0.13^{\mathrm{b}}$ \\
\hline Embryos weight (gm) & $1.64 \pm 0.15^{\mathrm{a}}$ & $1.84 \pm 0.14^{\mathrm{a}}$ & $6.23 \pm 0.04^{\mathrm{b}}$ \\
\hline Embryo length (cm) & $5.98 \pm 0.04^{\mathrm{a}}$ & $6.06 \pm 0.07^{\mathrm{a}}$ & \\
\hline
\end{tabular}

Note: Values are means \pm se $(n=6$ per group). Each value not sharing a common letter superscript is significantly different $(P<0.05)$.

\section{Discussion}

Infertility is an important public health problem and diagnosis and treatment are stressful, invasive, and costly [18]. Obesity and lifestyle factors such as cigarette smoking, alcohol use, and recreational drug use can promote excess free radical production, which could affect fertility [4]. Ech known as powerful antioxidant natural product which may improve fertility by prevent oxidative stress state. Oxidative stress is one of the most frequent problems in patients with obesity [19]. In the present study Ech showed hypolipidimic activity by decrease levels of TC, Tg, LDL-C and increase HDL-C. This improve in lipid profile state was confirmed by many previous studies [15] [14] and consider main factor for enhancing fertility. Female obesity and known to adversely affect fertility through changes of hormone patterns and the menstrual cycle [18]. Therefore, alterations in liver function due to alcohol consumption may result in altered metabolism of the exogenous gonadotropins used in In vitro fertilization, as well as the estrogen response of ovarian follicles to stimulation. In theory, these hormonal shifts could result in abnormal folliculo genesis and impaired endometrial receptivity [20].

Liver play essential role in the fertility where liver function affects the reproductiion by modulating sex steroid metabolism and transport to tissues [21]. Our study revealed that high dose of Ech improve liver function by decrease AST, ALT, ALP activities and increase protein production which consider other pathway for improve fertility. Maintained of kidney functions play important role in fertility.Renal insufficiency is usually accom?panied by impaired reproductive function, particularly among females [22]. The current study proved the ability of Ech to improve kidney functions which enhance fertility in female rats. Hyperglycemia and elevated lipids acutely suppress LH and FSH [23]. So, the hypoglycemia and hypolipidemic activities of Ech have amelioration effect on LH and FSH in the present study. In the present study uterus weight, body weight gain, placenta weight, embryos number, embryos weight, embryo length increased after the treatment with high dose Ech. An improvement in sex hormones, lipid profile, glucose level, liver function and kidney functions is the suggested pathways for amelioration the fertility in female rats.

\section{Conclusion}

Echinchrome ameliorate female rats' fertility through an improvement in sex hormones, lipid profile, glucose level, liver function and kidney functions.

\section{References}

1. Vander Borght M, Wyns C (2018) Fertility and infertility: Definition and epidemiology. Clin Biochem 62: 2-10.

2. Banerjee K, Singla B (2018) Acceptance of Donor Eggs, Donor Sperms, or Donor Embryos in Indian Infertile Couples. J Hum Reprod Sci 11(2): 169-171.

3. Kuroda K (2018) Unexplained Infertility: Introduction. In: Treatment Strategy for Unexplained Infertility and Recurrent Miscarriage pp. 3-5.

4. Agarwal A (2012) The effects of oxidative stress on female reproduction: a review. Reprod Biol Endocrinol 10: 49.

5. Yamamoto Y, Iwamoto T, Sato I, Lycopene, Tomatoes (2018) Male Infertility. In: In Lycopene and Tomatoes in Human Nutrition and Health pp. 103-128.

6. Yamaguchi K (2019) Tacrolimus treatment for infertility related to maternal-fetal immune interactions. Am J Reprod Immunol 81(4): e13097.

7. Linda J (2003) Osteoporosis Associated with the treatment of paraphilias: a clinical review of seven case reports. J Forensic Sci 48(4): 849-855.

8. Bhakuni DS, Rawat DS (2005) Bioactive Marine Natural Products. Anamaya Publishers, New Delhi, India.

9. Bragadeeswaran S (2013) Bioactive potential of sea urchin Temnopleurus toreumaticus from Devanampattinam, Southeast coast of India. J Pharm and Altern Med 2(3): 9-17.

10. Jeong SH (2014) Echinochrome a increases mitochondrial mass and function by modulating mitochondrial biogenesis regulatory genes. Mar Drugs 12(8): 4602-4615.

11. Anderson HA, Mathieson JW, Thomson RH (1969) Distribution of spinochrome pigments in echinoids. Comp Biochem Physiol 28(1): 333345 .

12. Jeong SH (2014) Echinochrome A protects mitochondrial function in cardiomyocytes against cardiotoxic drugs. Mar Drugs 12(5): 2922-2936. 
13. Seo DY (2015) Echinochrome A Improves Exercise Capacity during Short-Term Endurance Training in Rats. Mar Drugs 13(9): 5722-5731.

14. Soliman AM, Mohamed AS, Marie MAS (2016) Effect of Echinochrome on Body Weight, Musculoskeletal System and Lipid Profile of Male Diabetic Rats. Austin J Endocrinol Diabetes 3(2): 1045.

15. Soliman AM, Mohamed AS, Marie (2016) Echinochrome pigment attenuates diabetic nephropathy in the models of type 1 and type 2 diabetes. Diabetes Mellitus 19(6): 359-365.

16. Amarowicz R, Synowiecki J, Shahidi F (1994) Sephadex LH-20 separation of pigments from shells of red sea urchin (Strongylocentrotus franciscanus). Food Chem 51(2): 227-229.

17. Kuwahara R (2009) Antioxidant property of polyhydroxylated naphthoquinone pigments from shells of purple sea urchin Anthocidaris crassispina. LWT Food Science Technol 42(7): 1296-1300.
18. Ruder EH, Hartman TJ, Goldman MB (2009) Impact of oxidative stress on female fertility. Curr Opin Obstet Gynecol 21(3): 219-222.

19. Yang RL (2008) Increasing Oxidative Stress with Progressive Hyperlipidemia in Human: Relation between Malondialdehyde and Atherogenic Index. J Clin Biochem Nutr 43(3): 154-158.

20. Van Heertum K, Rossi B (2017) Alcohol and fertility: how much is too much. Fertil Res Pract 3: 10 .

21. Grossmann M (2019) Reproductive Endocrinology of Nonalcoholic Fatty Liver Disease. Endocr Rev 40(2): 417-446.

22. Ghazizade S (2007) Infertility among Kidney Transplant Recipients. Saudi J Kidney Dis Transp 18(1): 79-82.

23. Chosich J (2017) Acute Recapitulation of the Hyperinsulinemia and Hyperlipidemia characteristic of Metabolic Syndrome suppresses Gonadotropins. Obesity (Silver Spring) 25(3): 553-560. 